
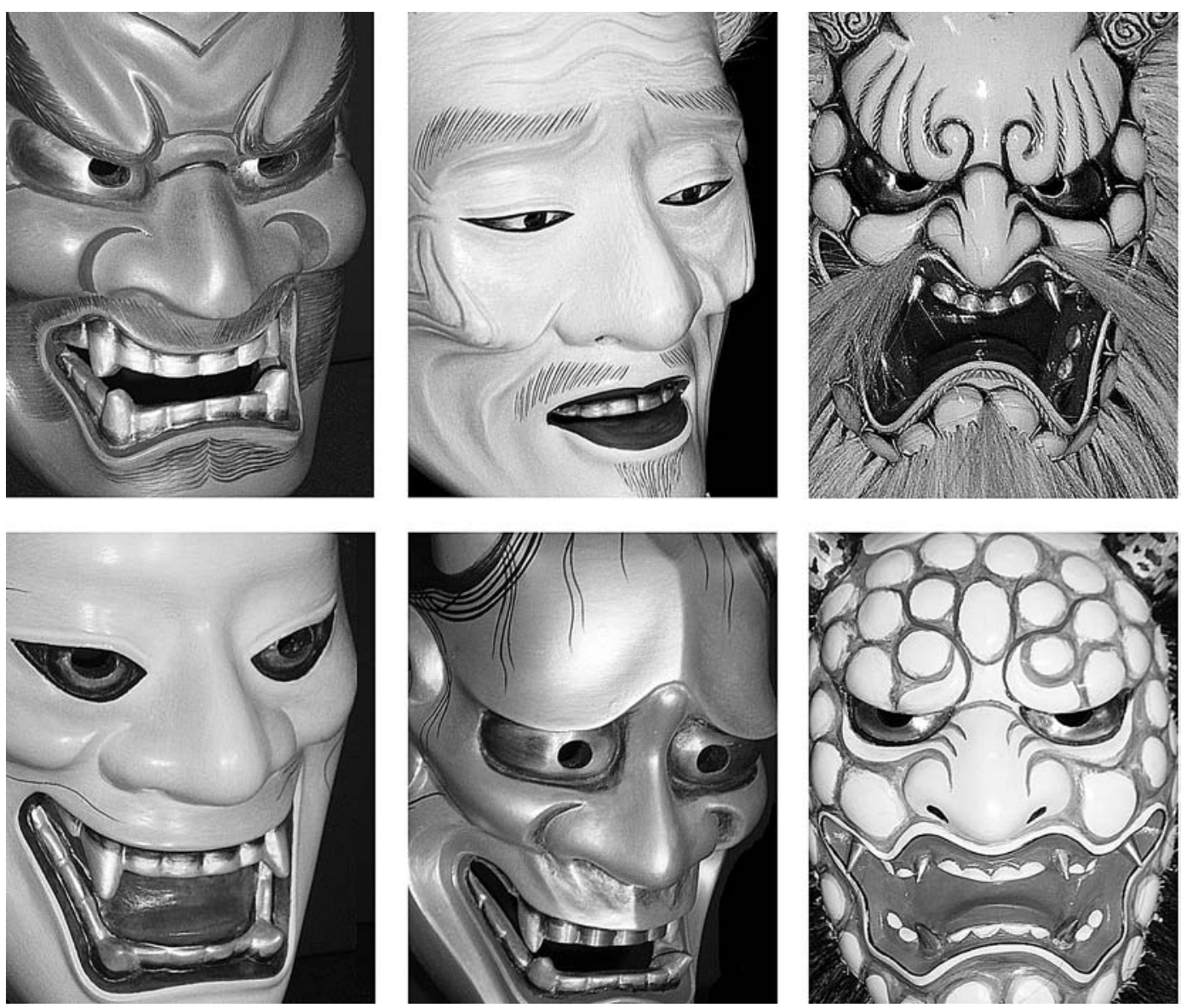

\title{
Navegar com rumo
}

\section{Rui Monteiro}

A alguns cliques de distância, em meia-dúzia de pequenos gestos, um mundo de informação está sempre disponivel no monitor de um computador. É um paraíso com o seu lado infernal, porque, embora finito, o ciberespaço é ainda assim demasiado vasto para o utilizador desprevenido. E como se pode verificar realizando uma busca sobre qualquer tópico, é preciso abrir muitas ostras para encontrar uma pérola.

Em números redondos, anda ai pelos 100 milhões a quantidade de referências encontradas na Internet, no principio de Dezembro, após uma busca no Google (www.google.pt), usando a palavra-chave "teatro" em diversas linguas. Este espantoso número engloba entradas em português, castelhano, francês, alemão e inglês (naturalmente a lingua campeã, com quase 80 milhões de linques) e inclui os mais variados temas, desde a escrita à programação, passando pela encenação, o ensino, a interpretação, os aparatos técnicos, o agenciamento, a angariação de fundos, ou mesmo a arquitectura das salas e dos palcos, o emprego e o trabalho precário, a História e as histórias, o camarim perfeito, a costureira ideal, a tese adequada, enfim, praticamente tudo o que se quiser. Se a este número se juntarem mais uns milhões de páginas de crítica publicadas pela imprensa de todo o mundo e disponiveis na Internet, a somar às outras centenas de boletins de periodicidade mais ou menos informal, o resultado só pode ser verdadeiramente extraordinário (e ainda falta contar os blogues). No entanto, neste mar de oportunidades de informação e de pesquisa, nem tudo o que vem na rede é peixe.

É um facto da vida na Internet que, entre as ligações seleccionadas por um qualquer motor de busca, é sensato esperar encontrar umas centenas desactivadas, ou sem actualização há meses e anos, muitos linques repetidos e uma quantidade elevada de sitios que, bem vendo as coisas, não interessam a ninguém. De qualquer maneira, basta esgravatar a superficie, isto é, as primeiras vinte ou trinta páginas de uma pesquisa no Google, para achar sítios para todos os gostos e quaisquer necessidades.

Um bom ponto de partida, por separarem grande parte do trigo do joio, são os portais (por exemplo: http.//www.theatrelinks.com/, http://vl-theatre.com/, http://www.etc-centre.org/home.asp,

http://www.londontheatre.co.uk/, http://www.cnt.asso.fr/), espécie de Páginas Amarelas da net que permitem iniciar as buscas a partir de tópicos pré-determinados. De qualquer maneira, descontando desde já a crítica, o que mais se encontra são páginas de teatros e de companhias, de 

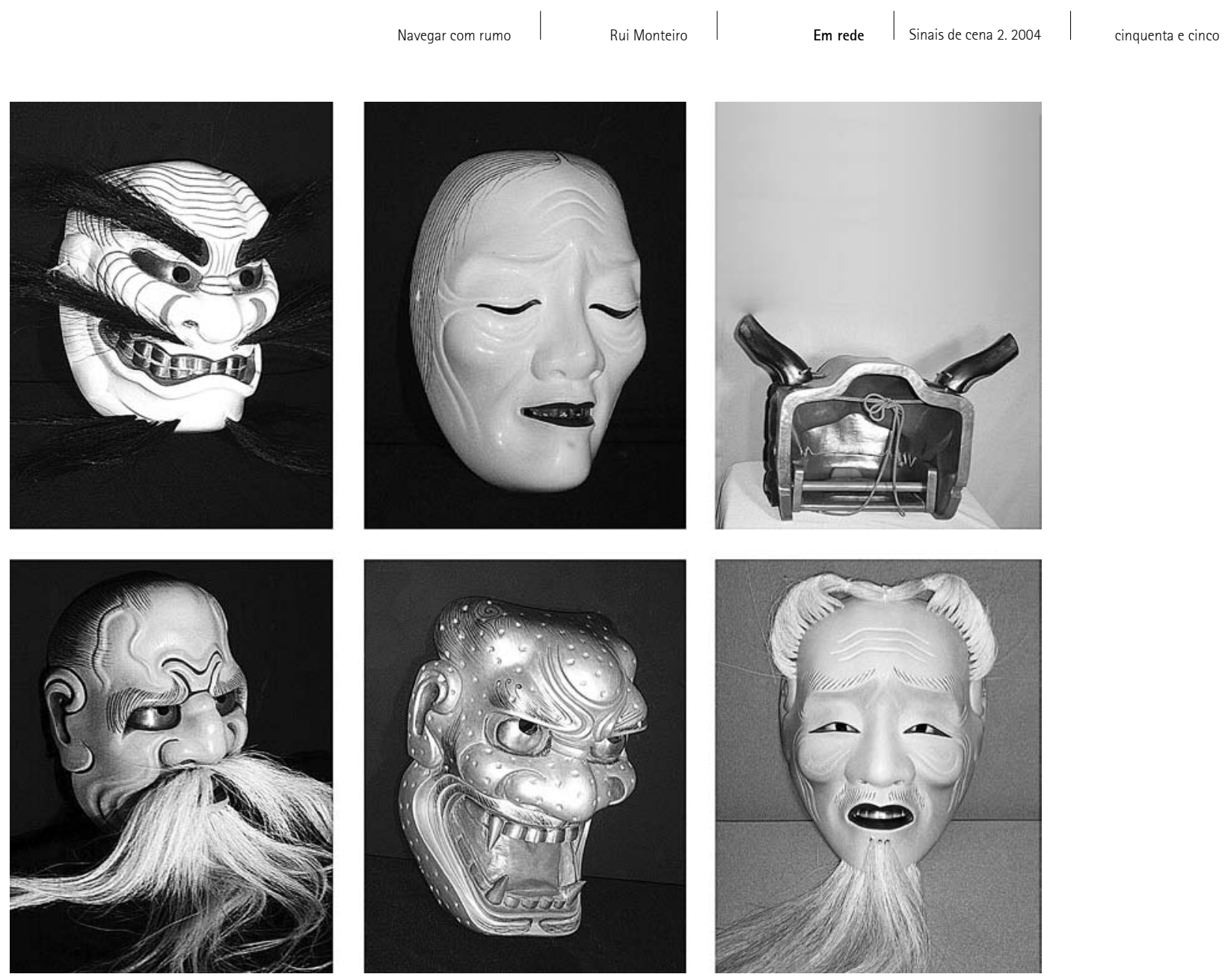

associações profissionais, páginas pessoais de actores e dramaturgos, instituições estatais e privadas, guias de espectáculos por cidades, programas, ocasionalmente extractos de espectáculos em vídeo, estudos e pesquisas académicas; sem esquecer alguns de carácter comercial, geralmente livrarias e fornecedores de equipamentos - e até coisas mais inesperadas, como um peculiar sitio de venda de máscaras de teatro nô

(http://www.nohmask21.com/), em que se pode apreciar a beleza de mais de meia centena de reproduções e ainda recolher alguma informação histórica. $E_{1}$ claro, grupos de discussão, geralmente animados por amadores (mais de treze mil em português, grande parte deles de origem brasileira, e perto de três milhões em inglês).

0 sitio português Teatro Links

(http://teatrolinks.com.sapo.pt/), criado e mantido por Leonardo Lisboa, é um estimulante porto de partida para a navegação e busca através da coisa teatral em Portugal e no estrangeiro. Na página de entrada, ladeada por duas colunas de linques, encontram-se em destaque algumas peças em cena, quase sempre com uma ligação que dá acesso à sinopse e ficha técnica do espectáculo, que pode incluir ainda biografias e informação sobre o autor e a companhia. Para completar esta informação, o responsável acrescentou uma secção que permite aceder às principais agendas culturais publicadas em Portugal na Internet.

0 sumo deste portal são as suas colunas de linques laterais. Nacionais à esquerda, estrangeiros à direita, permitem uma razoável navegação pelo mundo do teatro através do ciberespaço, seja o interesse profissional ou meramente "turístico". Na secção portuguesa, encontramse ligações para os sítios de instituições profissionais, académicas e estatais, companhias, teatros e salas e ainda uma listagem dos principais cursos de teatro. Do lado estrangeiro a organização é idêntica, mas inclui ainda páginas de critica, entradas para autores e dramaturgia, guarda-roupa e cenografia, uma exótica secção de teatro oriental, mais uma lista de festivais internacionais de teatro.

0 senão desta bela é, antes de mais, o seu descuidado aspecto gráfico. Depois, um trabalho de actualização de linques é de toda a conveniência, assim como uma melhor organização da barra de navegação superior. Fundamental, porém, é a ocupação dos espaços dedicados e já reservados a notícias, opinião e críticas que permitirão a Teatro Links uma maior eficácia e, quem sabe, a sua transformação de instrumento apenas utilitário em local de encontro e discussão. 